\title{
Female adnexal tumors of probable Wolffian origin: morphological, immunohistochemical, and molecular analysis of 15 cases
}

\author{
Jennifer A. Bennett ${ }^{1}$ Lauren L. Ritterhouse $\mathbb{1}^{1} \cdot$ Larissa V. Furtado $^{2} \cdot$ Ricardo R. Lastra $^{1} \cdot$ Anna Pesci $^{3}$. \\ Jordan M. Newell ${ }^{4}$ Eike Burandt ${ }^{5} \cdot$ Loes Kooreman $^{6} \cdot$ Koen Van de Vijver $\oplus^{7} \cdot$ Thomas Krausz $^{1} \cdot$ Ana Felix $^{8}$. \\ Gian Franco Zannoni ${ }^{9} \cdot$ Robert H. Young $^{10} \cdot$ Esther Oliva $^{10}$
}

Received: 22 July 2019 / Revised: 4 September 2019 / Accepted: 6 September 2019 / Published online: 7 October 2019

(c) The Author(s), under exclusive licence to United States \& Canadian Academy of Pathology 2019

\begin{abstract}
Female adnexal tumors of probable Wolffian origin are rare and present a diagnostic challenge due to their morphological and immunohistochemical overlap with more common ovarian and broad ligament entities. We evaluated the morphological, immunohistochemical, and molecular features of 15 tumors of probable Wolffian origin. Patients ranged from 32 to 69 (mean 47) years and tumors from 1.8 to 30 (mean 10) $\mathrm{cm}$. All except one arose in para-adnexal soft tissues. Follow-up was available for six patients, five of whom were alive and well, while the sixth, who had extra-adnexal disease at diagnosis, died from unrelated causes. The following patterns were noted: tubular (all tumors), solid 11/15 (73\%), sieve-like 7/15 (47\%), and reticular 1/15 (7\%). A myxoid background was present in 3/15 (20\%) of tumors and eosinophilic luminal secretions in 11/15 (73\%). Most tumors $(12 / 15,80 \%)$ had low-grade nuclear atypia, while three showed foci with scattered high-grade atypia. Mitotic index ranged from 0 to 17 (mean 4) per ten high-power fields. Tumors were positive for pankeratin and negative for TTF-1. EMA, GATA3, and PAX8 were positive in 2/10 (20\%; focal), $3 / 15$ (20\%; focal), and 1/15 (7\%; focal) of tumors, respectively. CD10, SF-1, calretinin, inhibin, ER, PR, cytokeratin 7, and WT1 were variably expressed. Pathogenic mutations were rare and included STK11 $(n=3), A P C(n=1)$, and MBD4 $(n=1)$. Copy number variations were detected in the three tumors with STK11 mutations and a myxoid background. These data demonstrate that female adnexal tumors of probable Wolffian origin are morphologically and immunohistochemically diverse, but infrequently harbor pathogenic mutations. However, their lack of mutations in contrast to their mimickers may be a valuable tool in diagnostically difficult cases.
\end{abstract}

Supplementary information The online version of this article (https:// doi.org/10.1038/s41379-019-0375-9) contains supplementary material, which is available to authorized users.

Jennifer A. Bennett

jabennett@bsd.uchicago.edu

1 Department of Pathology, University of Chicago Medical Center, Chicago, IL, USA

2 Department of Pathology, University of Utah and ARUP Laboratories, Salt Lake City, UT, USA

3 Department of Pathology, IRCCS Ospedale Sacro Cuore Don Calabria, Negrar, Verona, Italy

4 Department of Pathology, Penn State Milton S. Hershey Medical Center, Hershey, PA, USA

5 Department of Pathology, University Medical Center HamburgEppendorf, Hamburg, Germany

\section{Introduction}

Female adnexal tumors of probable Wolffian origin were formally described by Kariminejad and Scully in 1973 who first postulated their origin from adnexal mesonephric remnants [1], a theory that has been further supported by

6 Department of Pathology and GROW School for Oncology and Developmental Biology, Maastricht University Medical Center+, Maastricht, the Netherlands

7 Department of Pathology, Cancer Research Institute Ghent and University Hospital Ghent, Ghent, Belgium

8 Department of Pathology, Instituto Portugues de Oncologia de Lisboa and CEDOC, Lisbon, Portugal

9 Department of Pathology, Catholic University of Sacred Heart, Rome, Italy

10 Department of Pathology, Massachusetts General Hospital, Boston, MA, USA 
immunohistochemistry and electron microscopy findings. It has been speculated that the Wolffian system is comprised of two zones (upper and lower), and that mesonephric remnants from each zone, as well as related tumors are distinct [2]. A differing immunohistochemical profile of mesonephric tumors from the upper and lower zones supports this hypothesis. Whereas mesonephric carcinomas of the cervix are typically positive for GATA3 (variable extent and intensity) and PAX8 [3-9], most female adnexal tumors of probable Wolffian origin are negative for these markers [6, 10-13]. Furthermore, periadnexal mesonephric remnants tend to be PAX8 negative and at most, focally GATA3 positive, while those in the corpus, cervix, and vagina are diffusely positive for both markers [6, 14-16]. Targeted next-generation sequencing has identified recurring mutations in KRAS, NRAS, and chromatin remodeling genes, as well as copy number variations in mesonephric carcinomas of the cervix [17]. However, none of these mutations or copy number variations have been identified in the 11 female adnexal tumors of Wolffian origin sequenced to date [11, 13, 17]. Instead, STK11 mutations have been identified in two tumors and $K M T 2 D$ variants in four [13]. Herein we describe the clinicopathological and immunohistochemical features, as well as the molecular profile of 15 female adnexal tumors of probable Wolffian origin, compare our findings with those reported in the literature, and discuss their implications and possible role in the differential diagnosis.

\section{Materials and methods}

\section{Clinicopathological evaluation}

After approval by the institutional review board, in-house surgical pathology archives at the Massachusetts General Hospital, as well as personal consultation files of the late Dr Robert E. Scully and two of the coauthors (RHY and EO), were searched for all female adnexal tumors of probable Wolffian origin, resulting in 15 cases. Age, clinical status, and follow-up were retrieved from the medical records or consulting pathologist if available. Macroscopic features including tumor size, location, and presence of extra-adnexal disease at diagnosis were obtained from pathology reports. The percentage of tubular, solid, sieve-like, and reticular growth was estimated, and the background stroma, presence of spindling of tumor cells, necrosis, intratumoral hyalinization, luminal secretions, and a glomeruloid appearance was noted. Cellular atypia was graded as low or high (cells with a prominent nucleolus greater than two times the size of a lymphocyte), and the mitotic index per ten high-power fields was recorded.

\section{Immunohistochemistry}

If not previously performed, primary monoclonal antibodies to CAM5.2 (clone CAM5.2, dilution 1:100; BD Biosciences, San Jose, CA), CD10 (clone 56D6, dilution 1:100; Leica Biosystems, Buffalo Grove, IL), GATA3 (clone L50823, dilution 1:200; Cell Marque, Rocklin, CA), PAX8 (polyclonal, dilution 1:1000; Proteintech Group, Rosemont, IL), SF-1 (clone N1665, dilution 1:200; Thermo Fisher Scientific, Waltham, MA), and vimentin (clone V9, dilution 1:2000; DAKO, Santa Clara, CA) were applied to a representative $5-\mu \mathrm{m}$ thick section of formalin-fixed, paraffinembedded tumor. Appropriate controls were run in tandem. Antibodies were considered positive if nuclear (GATA3, PAX8, SF-1), cytoplasmic (CAM5.2, vimentin), or cytoplasmic/membranous (CD10) staining was present, and interpreted as diffusely positive ( $>50 \%$ staining), focally positive $(<50 \%$ staining), or negative.

\section{University of Chicago Medicine Oncoplus next- generation sequencing}

Genomic DNA was isolated from macro-dissected formalinfixed paraffin-embedded sections using the QIAamp DNA FFPE Tissue Kit (Qiagen, Valencia, CA) according to the manufacturer's instructions. Next-generation sequencing was performed using the targeted, hybrid capture 1213-gene OncoPlus panel, as previously described [18]. In brief, following extraction, DNA was quantified using the Qubit fluorometric assay (Thermo Fisher Scientific, Foster City, CA) and further assessed for quantity and quality using a quantitative polymerase chain reaction assay (hgDNA Quantitation and QC kit, Kapa Biosystems, Wilmington, MA). Library preparation and sequencing were performed as previously described [18]. Briefly, $100 \mathrm{ng}$ of DNA was fragmented using the Covaris S2 (Covaris, Woburn, MA). The fragmented DNA was amplified using the KAPA HTP Library Preparation Kit (Kapa Biosystems) along with a set of patient-specific indices (Roche, Indianapolis, IN). The pooled library was captured using a custom SeqCap EZ capture panel (Roche) featuring a collection xGen Lockdown Probes (IDT, Coralville, IA) for 1213 genes (Supplementary Table 1). The pooled, captured library was sequenced on the Illumina HiSeq 2500 system (Illumina, San Diego, CA) in rapid run mode $(2 \times 101 \mathrm{bp}$ paired end sequencing). Somatic mutation calling was performed across all 1213 genes using a custom in-house bioinformatics pipeline previously described [18]. Variants were annotated using Alamut Batch, Version 1.4 (Rouen, France).

Variant review was performed by a molecular pathologist (LLR) and included filters based on population variant frequencies (Exome Aggregation Consortium, http://exac. broadinstitute.org/), variant frequencies in cancer databases (COSMIC: of somatic mutations in cancer https://cancer.sa 
nger.ac.uk/cosmic and cBioPortal https://www.cbioportal. org/), and coding effects. Somatic variant calls were inspected using Integrated Genomics Viewer (IGV; Broad Institute, MIT Harvard, Cambridge, MA).

\section{University of Chicago Medicine RNA fusion next- generation sequencing}

RNA was obtained from formalin-fixed paraffin-embedded sections followed by RNA-Seq library preparation. Ribosomal depletion was carried out prior to RNA-Seq library preparation (Stranded RNA-Seq Library Preparation Kit, Kapa Biosystems, Wilmington, MA). Libraries were subjected to capture targeting 1213 cancer-related genes (Supplementary Table 1) followed by sequencing via HISeq 2500 (Illumina, Inc., San Diego, CA). Bioinformatic pipelines for detection of fusion reads included a combination of in-house fusion detection software utilizing both discordant and split reads and publicly available STAR-fusion software [19].

\section{ARUP TruSight Oncology 500 next-generation sequencing}

The TruSight Oncology 500 (TSO 500, Illumina, Inc., San Diego, CA) assay was used to search for genomic alterations in the seven tumors that failed quality control measures in OncoPlus, as well as one additional neoplasm. DNA was extracted from formalin-fixed, paraffin-embedded tumor samples using the AllPrep DNA/RNA formalinfixed, paraffin-embedded kit (Qiagen Inc, Germantown, MD). Following extraction, genomic DNA was quantified using the Qubit fluorometric assay (Thermo Fisher Scientific, Carlsbad, CA), and $50 \mathrm{ng}$ were sheared via sonication in a Covaris LE220 instrument (Covaris, Woburn, MA). Following sonication, DNA was end-repaired and a poly-A tail was added. Unique molecular identifier sequences, along with adapter sequences, were ligated to each molecule to aid in downstream polymerase chain reaction duplicate removal and more accurate variant identification. Two subsequent rounds of hybridization, capture, and washing were performed using probes complimentary to the regions of interest of the 523 genes covered by the assay (Supplemental Table 2). The DNA libraries were then amplified, cleaned, and quantified to ensure successful enrichment and capture of the samples. Libraries from these eight tumors were then normalized, pooled, and sequenced using Illumina's NextSeq 500 High Output kit with 150 cycle chemistry.

Data processing, analysis, and variant annotation were performed on Illumina's TSO 500 bioinformatics pipeline by a molecular pathologist (LVF). Variants with $>100 \times$ depth and $>5 \%$ allele frequencies were used for further interpretation. Additional filters were used on the annotated files based on population variant frequencies (gnomAD: genome aggregation database https://gnomad. broadinstitute.org/ and dbSNP database https://www.ncbi. nlm.nih.gov/snp) (to remove inherited singlenucleotide polymorphisms), variant frequencies in cancer databases (COSMIC: catalogue of somatic mutations in cancer https://cancer.sanger.ac.uk/cosmic and cBioPortal https://www.cbioportal.org/), and coding effects to return a final list of somatic variants that were used for interpretation. Somatic variant calls were inspected using Integrated Genomics Viewer (IGV; Broad Institute, MIT Harvard, Cambridge, MA).

\section{Results}

\section{Clinicopathologic evaluation}

Clinicopathological features are summarized in Table 1. Patients ranged from 32 to 69 (mean 47, median 45; unavailable in one) years and tumors from 1.8 to 30 (mean 10 , median 8.5 ; unavailable in two) $\mathrm{cm}$. Most tumors (13/ $14,93 \%$; unknown in one) were located in adnexal soft tissue (mesosalpinx-7, broad ligament-3, not specified-3), while one was centered in the ovary. Extra-adnexal disease at time of surgery was present in $2 / 14$ (14\%; unknown in one) of patients and involved either the omentum (case 3) or both the omentum and sigmoid peritoneum (case 5). Follow-up was available for six patients and ranged from 1 to 14 (mean 7 , median 6) years. The patient with omental and sigmoid peritoneal metastases (case 5) died from unrelated causes three years later, but did not experience recurrence of her Wolffian tumor. The remaining five patients, all of whom had adnexal-confined disease, were alive and well.

The number of hematoxylin and eosin slides ranged from 1 to 20 (mean 8, median 6). Tubular growth was noted in all neoplasms and was the dominant pattern in 12/15 (80\%) (Fig. 1a). Solid growth with a spindled appearance was present in 11/15 (73\%) of tumors and dominant in 2/15 (13\%) (Fig. 1b). A sieve-like pattern was noted in $7 / 15$ (47\%) of neoplasms (Fig. 1c), whereas $1 / 15(7 \%)$ showed reticular growth. Collagenous bands of stroma imparting a nodular pattern were seen in $8 / 15$ $(53 \%)$ of tumors, and a prominent myxoid matrix in $3 / 15$ (20\%). Eosinophilic luminal secretions (Fig. 1d) were identified in $11 / 15(73 \%)$ of tumors, intratumoral hyalinization in $5 / 15$ (33\%), infarct-type necrosis in $4 / 15$ (27\%), basophilic intraluminal secretions in 3/15 (20\%), and a glomeruloid appearance in 1/15 (7\%). Most neoplasms $(12 / 15,80 \%)$ had low-grade cytologic atypia; however, three tumors (cases 3, 5, and 12) showed scattered foci of high-grade atypia, characterized by lack of 


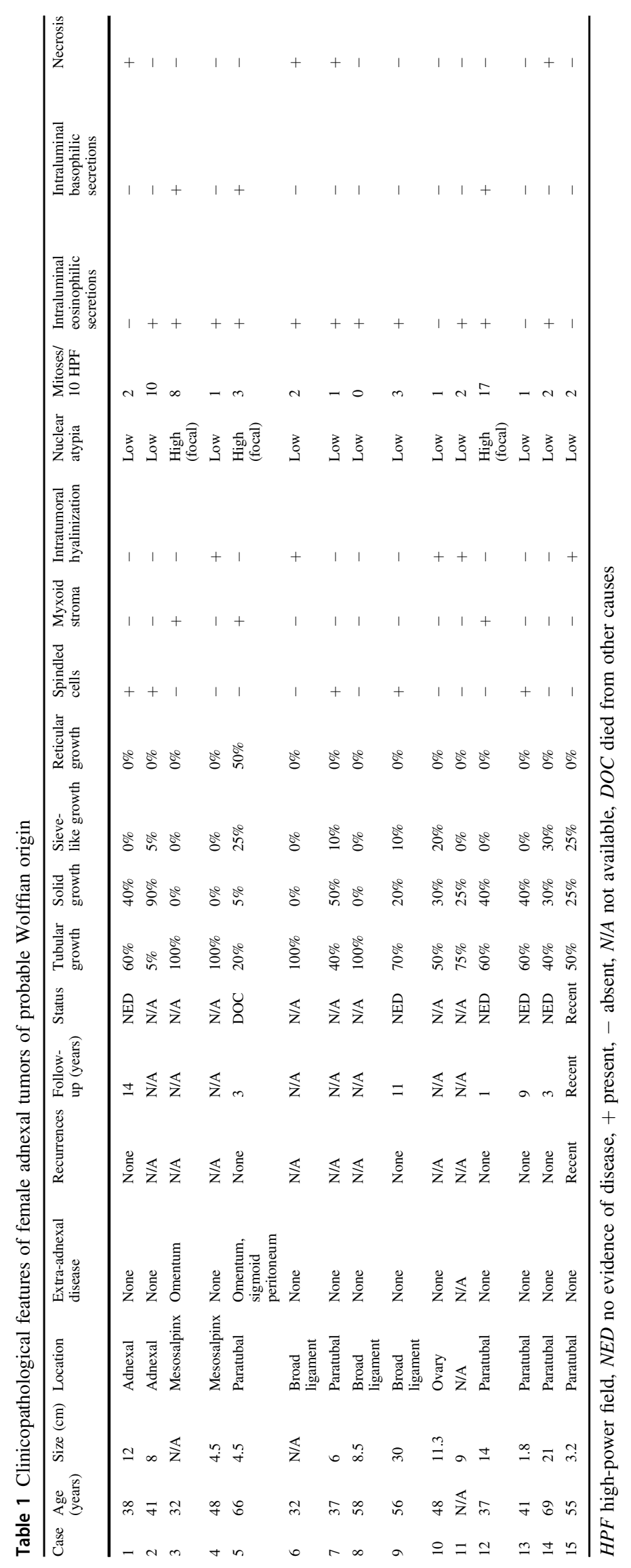



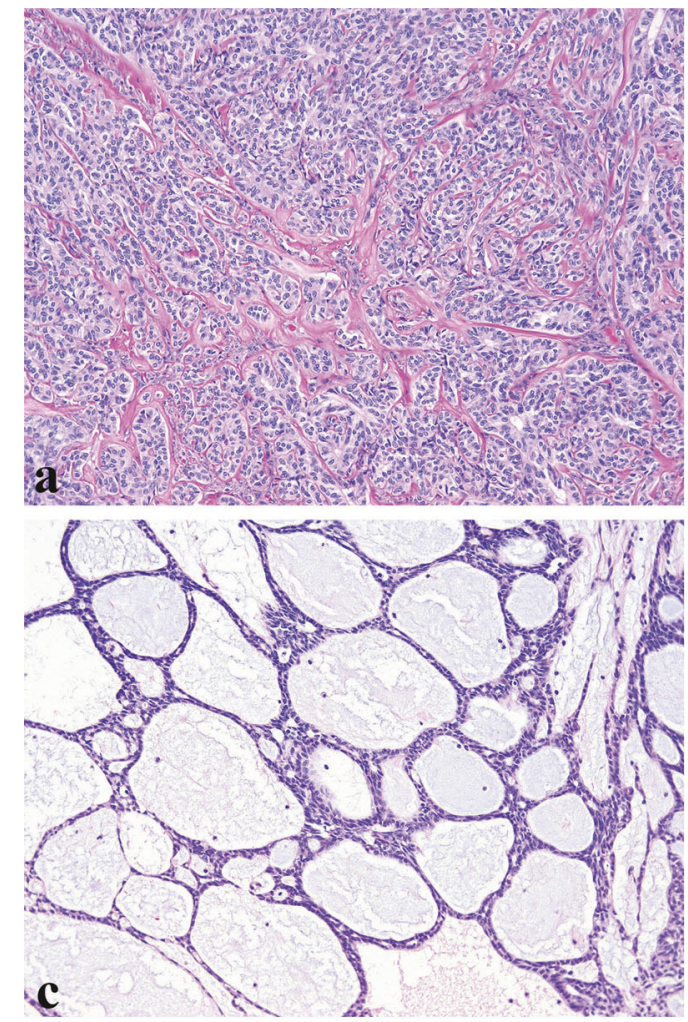

Fig. 1 Closely packed tubules with narrow lumens occasionally intersected by thin collagen bands (a). Solid growth with spindled cells (b). Sieve-like growth of cystically dilated glands with a "punched-

uniformity, nuclear enlargement, and prominent nucleoli. The mitotic index ranged from 0 to 17 (mean 4, median 2) per ten high-power fields.

\section{Immunohistochemistry}

Immunohistochemical results are summarized in Table 2 and highlighted in Fig. 2. All tumors $(15 / 15,100 \%)$ were positive for broad spectrum cytokeratin (CAM5.2 and/or AE1/AE3; 14 diffuse, 1 focal). CD10 and vimentin were each expressed in 14/15 (93\%; four diffuse, ten focal; and all diffuse, respectively), ER in $6 / 8$ (75\%; three diffuse, three focal), SF-1 in 11/15 (73\%; nine diffuse, two focal), inhibin in 8/11 (72\%; three diffuse, five focal), cytokeratin 7 in $4 / 6$ (67\%; three diffuse, one focal), calretinin in $4 / 7$ (57\%; three diffuse, one focal), WT1 in 4/7 (57\%; all diffuse), PR in 3/7 (43\%; one diffuse, two focal), GATA3 in $3 / 15$ (20\%; all focal), EMA in 2/10 (20\%; both focal), and PAX8 in $1 / 15$ (7\%; focal). TTF-1 was negative in all tumors evaluated $(0 / 7)$.

\section{Next-generation sequencing}

Sequencing using the University of Chicago Medicine OncoPlus panel was successfully completed on seven
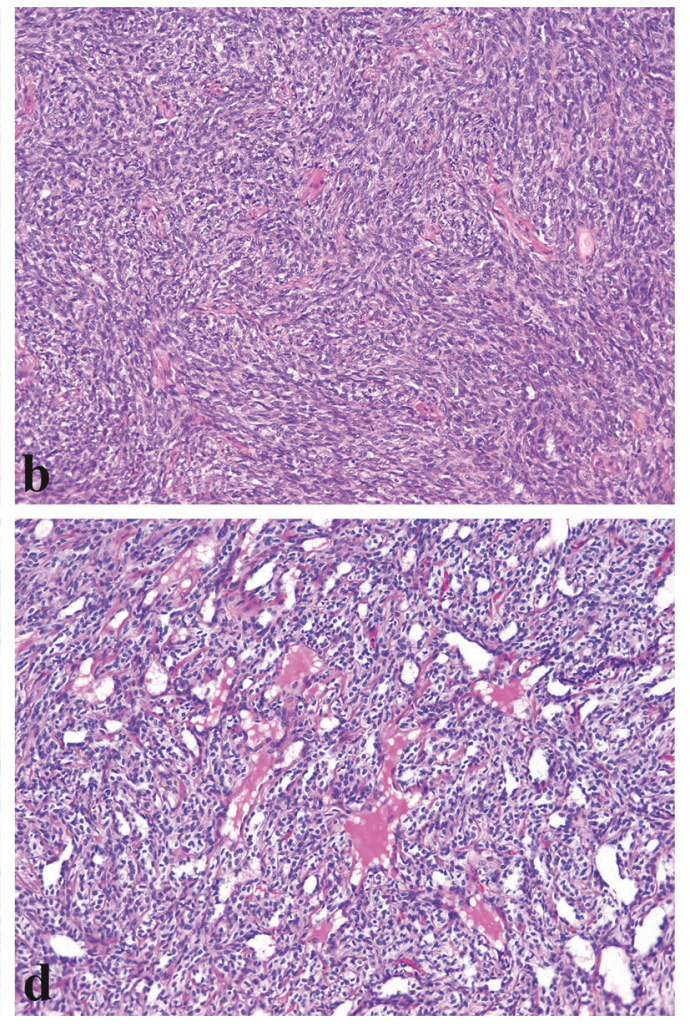

out" appearance (c). Eosinophilic luminal secretions in tubular lumens $(\mathbf{d})$

tumors with the remainder failing to meet quality control measures. Pathogenic variants were identified in 5/7 (71\%) of tumors (cases 1, 3, 5, 7, and 12) (Fig. 3a). STK11 mutations were seen in three tumors and included nonsense (p.W272*), frameshift (p.L201Cfs), and splicing (c.734 $+1 \mathrm{G}>\mathrm{A}$ ) mutations (cases 3,5 , and 12 , respectively). Two $A P C$ mutations were identified in case 1 and included $\mathrm{p}$. E1309Dfs and p.P1409Hfs, as well as a p.E314Rfs MBD4 mutation in case 7 . Variants of uncertain significance are listed in Supplemental Table 3. All tumors were microsatellite stable by next-generation sequencing. Arm-level copy number variations were identified in $3 / 7$ (43\%) of tumors (Fig. 3b). Copy number gains of $15 q$ were seen in all three neoplasms, loss of $1 p$ and gain of $15 p$ in two, and loss of $11 \mathrm{q}$ in two. No other recurrent arm-level copy number variations were observed. No fusions were identified in a subset of tumors for which sufficient RNA was available (cases 1, 3, 5, 7, 12, and 13).

On the TruSight panel, six of the eight tested tumors failed sequencing due to low quality of input material, as suggested by short DNA insert sizes (median size of $~ 60$ base pairs). No pathogenic variants were detected in the two tumors, for which sequencing results were available (cases 2 and 14). Variants of uncertain significance are highlighted in Supplemental Table 3. 
Table 2 Immunohistochemical profile of female adnexal tumors of probable Wolffian origin

\begin{tabular}{|c|c|c|c|c|c|c|c|c|c|c|c|c|c|c|}
\hline Case & $\begin{array}{l}\text { Broad spectrum } \\
\text { cytokeratin }\end{array}$ & EMA & Cytokeratin 7 & Vimentin & CD10 & Calretinin & Inhibin & ER & PR & WT1 & PAX8 & GATA3 & TTF-1 & SF-1 \\
\hline 1 & ++ & + & + & - & + & + & - & ++ & ++ & $\mathrm{NP}$ & - & - & - & - \\
\hline 2 & ++ & - & - & ++ & - & - & ++ & + & + & - & - & - & - & ++ \\
\hline 3 & ++ & + & NP & ++ & + & NP & NP & + & NP & NP & + & - & NP & - \\
\hline 4 & ++ & NP & NP & ++ & ++ & NP & NP & NP & $\mathrm{NP}$ & $\mathrm{NP}$ & - & + & NP & ++ \\
\hline 5 & ++ & - & ++ & ++ & + & ++ & + & ++ & + & ++ & - & - & - & - \\
\hline 6 & ++ & $\mathrm{NP}$ & NP & ++ & + & - & - & $\mathrm{NP}$ & NP & ++ & - & - & NP & ++ \\
\hline 7 & ++ & - & $\mathrm{NP}$ & ++ & + & $\mathrm{NP}$ & + & NP & $\mathrm{NP}$ & $\mathrm{NP}$ & - & - & $\mathrm{NP}$ & ++ \\
\hline 8 & + & $\mathrm{NP}$ & NP & ++ & + & $\mathrm{NP}$ & $\mathrm{NP}$ & $\mathrm{NP}$ & $\mathrm{NP}$ & $\mathrm{NP}$ & - & - & NP & + \\
\hline 9 & ++ & - & $\mathrm{NP}$ & ++ & ++ & ++ & + & - & - & - & - & - & - & ++ \\
\hline 10 & ++ & $\mathrm{NP}$ & NP & ++ & + & $\mathrm{NP}$ & NP & NP & NP & $\mathrm{NP}$ & - & + & $\mathrm{NP}$ & ++ \\
\hline 11 & ++ & - & $\mathrm{NP}$ & ++ & + & $\mathrm{NP}$ & + & $\mathrm{NP}$ & $\mathrm{NP}$ & $\mathrm{NP}$ & - & + & $\mathrm{NP}$ & ++ \\
\hline 12 & ++ & - & ++ & ++ & ++ & ++ & + & ++ & - & ++ & - & - & - & - \\
\hline 13 & ++ & NP & - & ++ & + & + & ++ & - & - & ++ & - & - & - & ++ \\
\hline 14 & ++ & - & ++ & ++ & ++ & - & - & + & - & - & - & - & - & + \\
\hline 15 & ++ & - & $\mathrm{NP}$ & ++ & + & $\mathrm{NP}$ & ++ & NP & $\mathrm{NP}$ & $\mathrm{NP}$ & - & - & NP & ++ \\
\hline
\end{tabular}

++ diffuse $(>50 \%),+$ focal $(<50 \%),-$ negative, $N P$ not performed

\section{Evaluation of STK11-mutated tumors}

The three tumors harboring pathogenic STK11 mutations (cases 3, 5, and 12) were seen in patients who were 32, 37, and 66 years, and two (cases 3 and 5) presented with extra-adnexal disease at diagnosis. Two tumors were tubular dominant, and one reticular, which showed a loose arrangement of thin and curvilinear cords of tumor cells in a myxoid background (Fig. 4a). Notably, tumor cells in these three neoplasms were associated with a prominent PAS-negative, mucicarminenegative myxoid matrix (Fig. 4b) - a feature that was absent in all other tumors in this series. For the most part, cytologic features were bland, but all neoplasms showed scattered foci with high-grade cytologic atypia (Fig. 4c). Mitotic index ranged from 3 to 17 per ten high-power fields, but necrosis was absent. The appearance seen in typical Wolffian tumors was only focally apparent in one (case 5); however, another tumor (case 3) was present adjacent to mesonephric remnants (Fig. 4d). All three neoplasms were positive for keratin, vimentin, CD10, and ER, but negative for SF-1. Two tumors (not tested in the third) were positive for WT1, calretinin, inhibin, and cytokeratin 7, but negative for TTF-1. Copy number variations were only detected in these three neoplasms. Follow-up was available for two patients-one was alive and well one year later (case 12), while the other died of unrelated causes three years following diagnosis (case 5).

\section{Discussion}

Female adnexal tumors of probable Wolffian origin are rare neoplasms that may be difficult to diagnose due to their morphologic overlap with more common entities especially in the ovary, but also at all sites by their lack of a defining immunophenotype. Herein, we sought to further elucidate these challenging neoplasms by performing a detailed clinicopathological, immunohistochemical, and molecular analysis of 15 tumors.

A variety of morphological patterns characterize female adnexal tumors of probable Wolffian origin, with the three main ones being tubular, solid, and sieve-like. At least two of these patterns were noted in 11/15 (73\%) of our tumors, while all three were present in $7 / 15(47 \%)$. The presence of multiple patterns often poses diagnostic difficulty with more common neoplasms, particularly endometrioid carcinomas and sex cord stromal tumors, and rarely mesotheliomas. While an origin in the adnexal soft tissue often suggests a Wolffian neoplasm, this is not so as a subset arise in the ovary [20]. Futhermore, endometrioid carcinomas (presumably arising from endometriosis) and sex cord stromal tumors [21] occasionally arise in adnexal soft tissue. Morphological features that help to distinguish a Wolffian tumor from an endometrioid carcinoma include background endometriosis/adenofibroma and squamous/mucinous differentiation in the latter. Other considerations are aided by the following: presence of Leydig cells and heterologous elements (Sertoli-Leydig cell tumor) or fibrothecomatous background, epithelial growth, and longitudinal nuclear grooves (adult granulosa cell tumor).

If morphology alone does not resolve the differential diagnosis, immunohistochemistry may be of some assistance. Female adnexal tumors of probable Wolffian origin show variable expression for a variety immunohistochemical markers, and our results herein mirrored the literature 

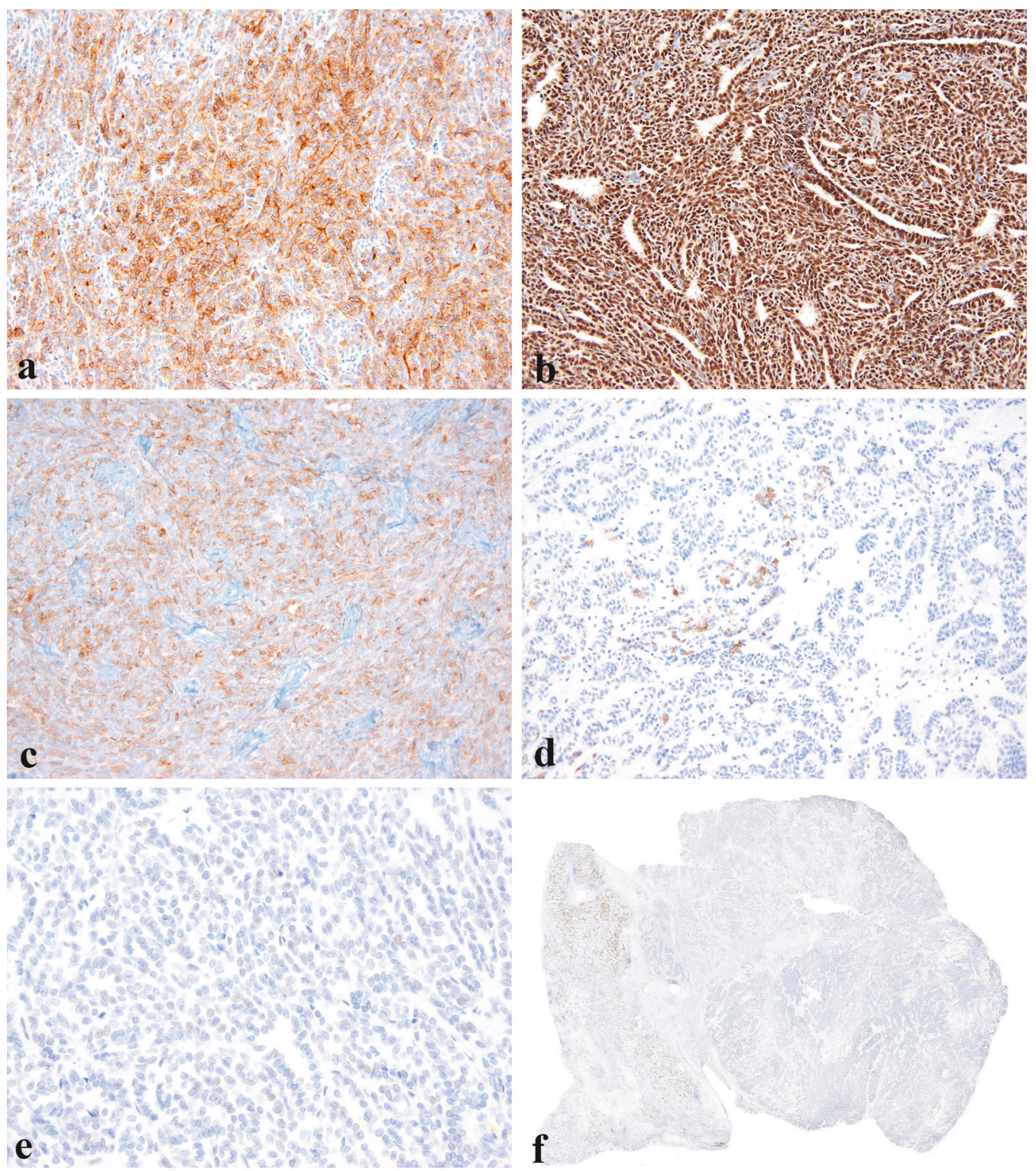

Fig. 2 CD10 (a), SF-1 (b), and inhibin (c) were expressed in most tumors. EMA (d), GATA3 (e), and PAX8 (f) were rarely positive with weak intensity

with only rare discrepancies (Table 3) [6, 10-14, 22-58]. We noted a higher rate of ER positivity ( $75 \%$ versus $31 \%$ ), which could possibly be attributed to a smaller number of tumors evaluated (6 versus 58), as well as inconsistency in the antibody clone used. While all 13 tumors previously evaluated for PAX8 were negative [10-13], we did detect focal positivity in one of our cases. Although PAX8 expression would raise suspicion for a carcinoma of Müllerian origin, it is important to note that rete ovarii is PAX8 positive [10]. Likewise, we noted focal weak GATA3 expression in three tumors, and while it has only been previously reported in one Wolffian tumor, up to $83 \%$ of upper mesonephric remnants are variably positive [6].
Nonetheless, despite the lack of a completely reproducible immunophenotype for female adnexal tumors of probable Wolffian origin, the overall staining profile may contribute to the correct diagnosis. Strong and diffuse EMA, PAX8, cytokeratin 7, ER, and vimentin are characteristic of endometrioid carcinoma, whereas the first two markers are typically negative or at most focally expressed in Wolffian tumors. Mesotheliomas show loss of BAP-1 in $~ 50 \%$ of tumors, and are diffusely EMA, cytokeratin 5/6, and D2-40 positive. To our knowledge, Wolffian tumors have not been evaluated for BAP-1 by immunohistochemistry, but mutations have not been detected in the current or previous studies $[13,17]$. 

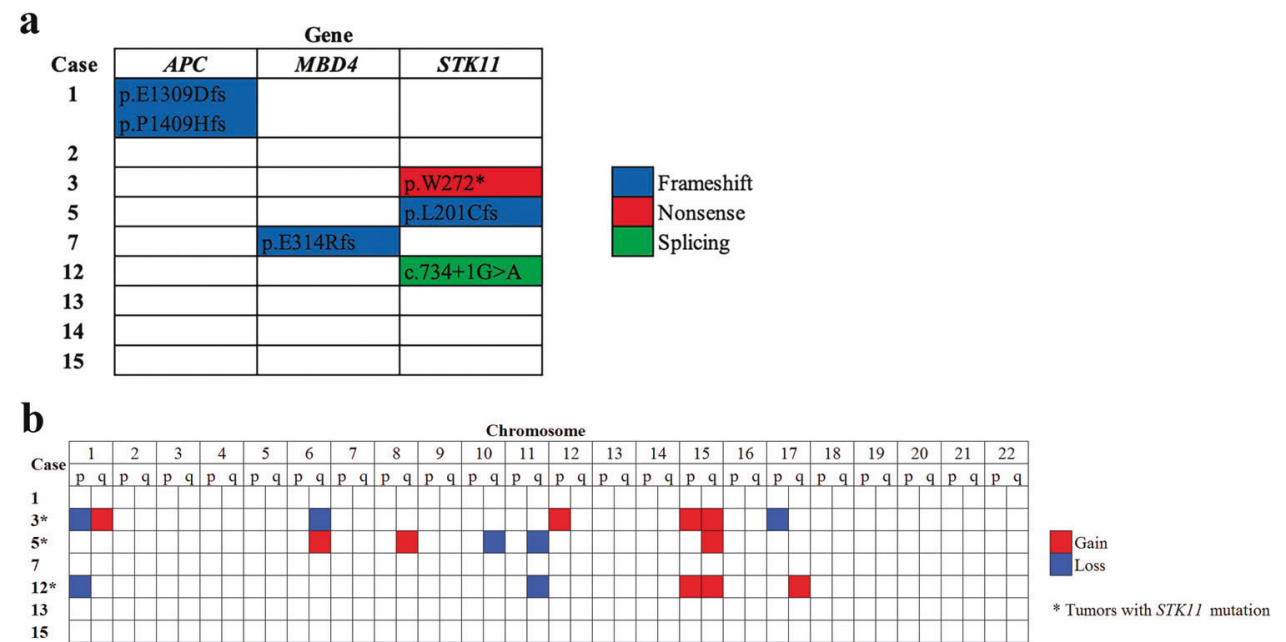

Fig. 3 Pathogenic mutations included STK11, APC, and MBD4 (a). Copy number variations were noted in tumors with STK11 mutations (b)

Fig. 4 Reticular pattern with a loose arrangement of tumor cells in a myxoid background (a). A striking myxoid matrix is noted and only present in tumors with STK11 mutations (b). Highgrade nuclear atypia $(\mathbf{c})$. Tumor is seen in close proximity to mesonephric remnants $(\mathbf{d})$
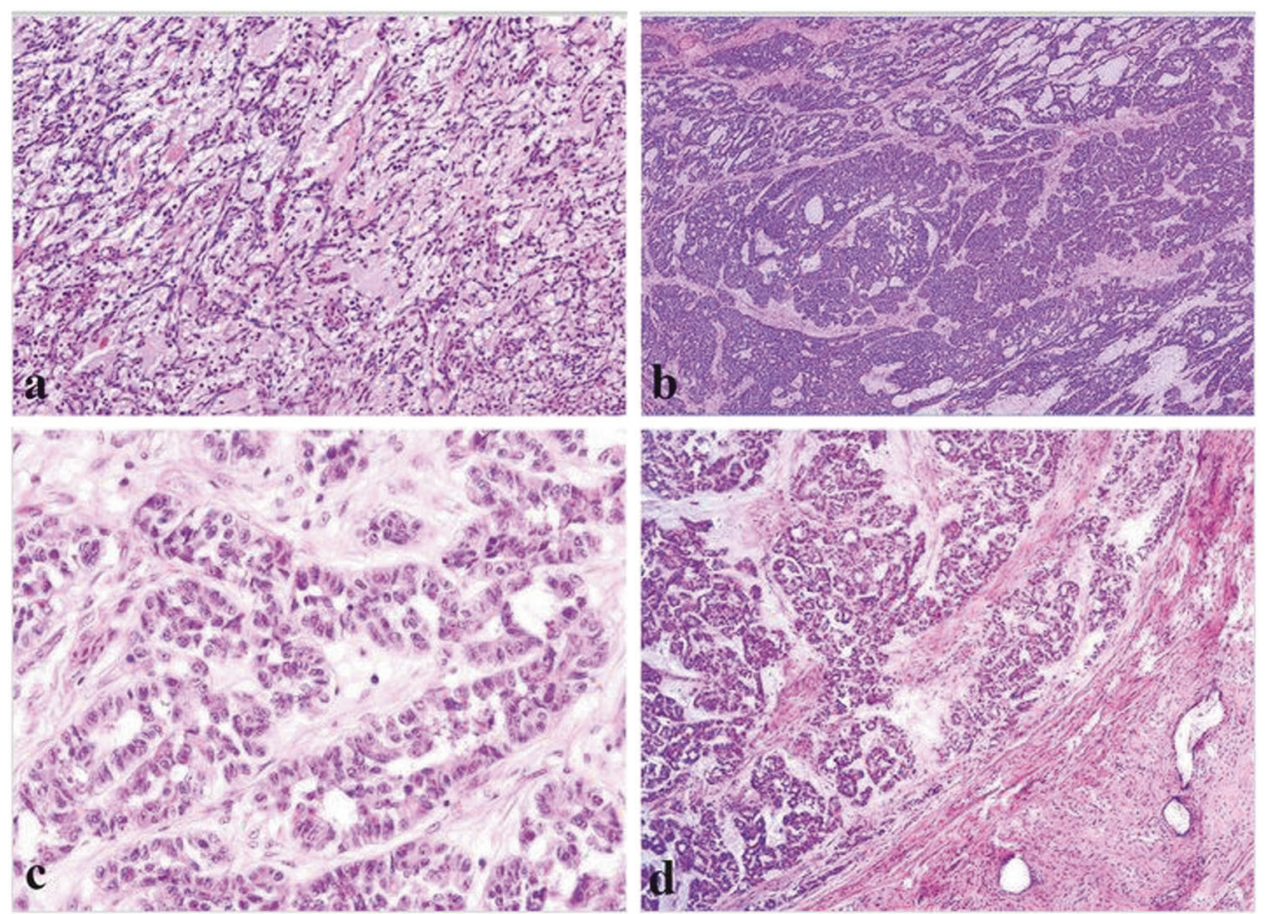

Differentiating Wolffian tumors from sex cord stromal tumors is more challenging since both may express calretinin, inhibin, WT1, and $\mathrm{CD} 10$, but are generally negative for EMA and PAX8. Historically, sex cord stromal tumors were characterized by diffuse inhibin positivity, whereas female adnexal tumors of probable Wolffian origin typically showed focal expression $[14,25,59]$. However, in the current study, as well as a recent series [60], inhibin was diffusely positive in $33 \%$ $(3 / 11)$ and $40 \%(2 / 5)$, respectively, making it a less reliable parameter to differentiate between the two entities. Other recently identified immunostains characteristic of sex cord origin include FOXL2 and SF-1 [43, 61]. Three Wolffian tumors have shown FOXL2 positivity on immunohistochemistry, but all lacked a FOXL2 mutation by real-time polymerase chain reaction [43]. While we did not perform FOXL2 immunohistochemistry on our tumors, all nine that were sequenced lacked evidence of a FOXL2 mutation. SF-1 was negative in $11 / 12$ (92\%) of previously reported female adnexal tumors of probable 


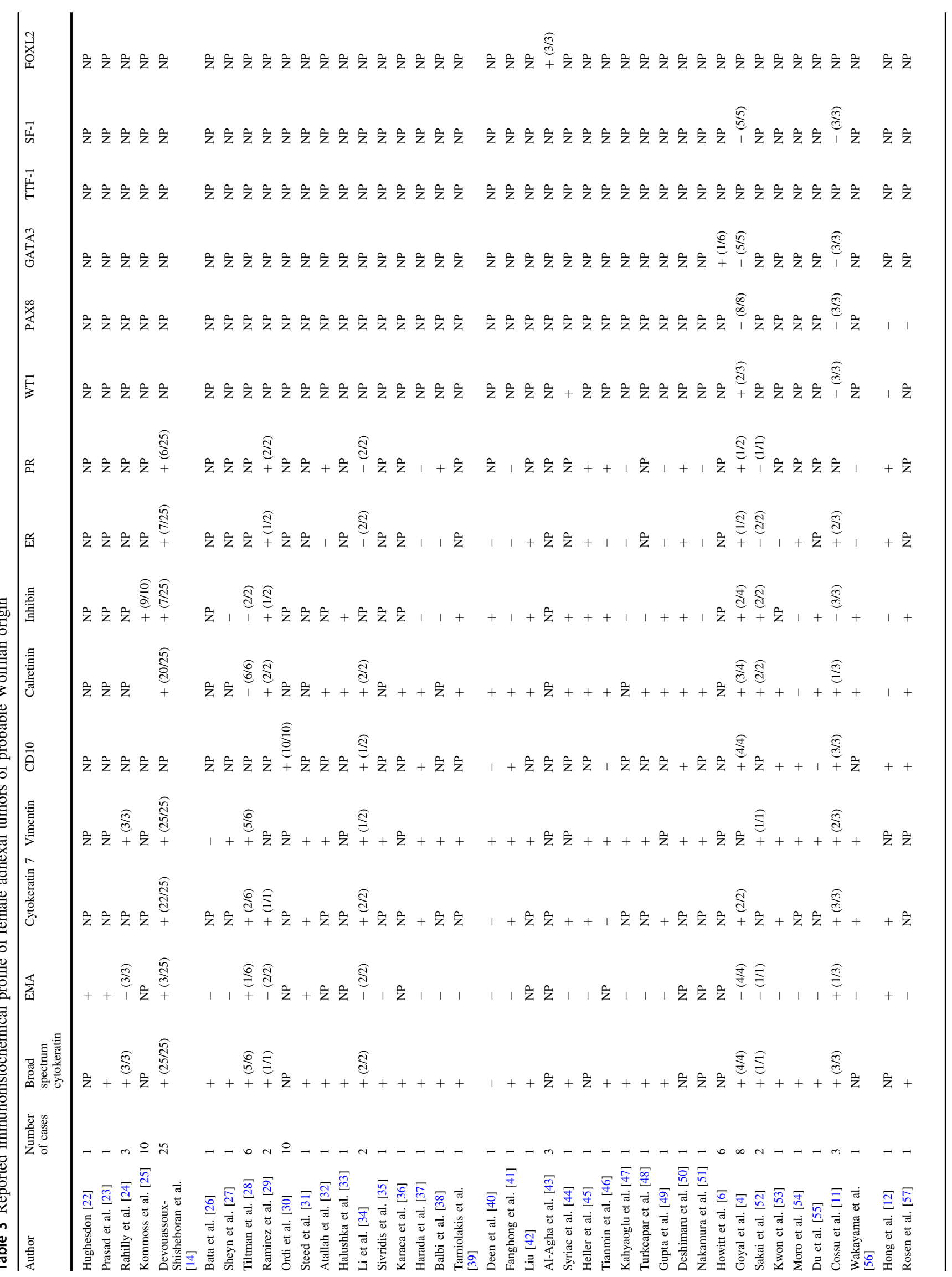




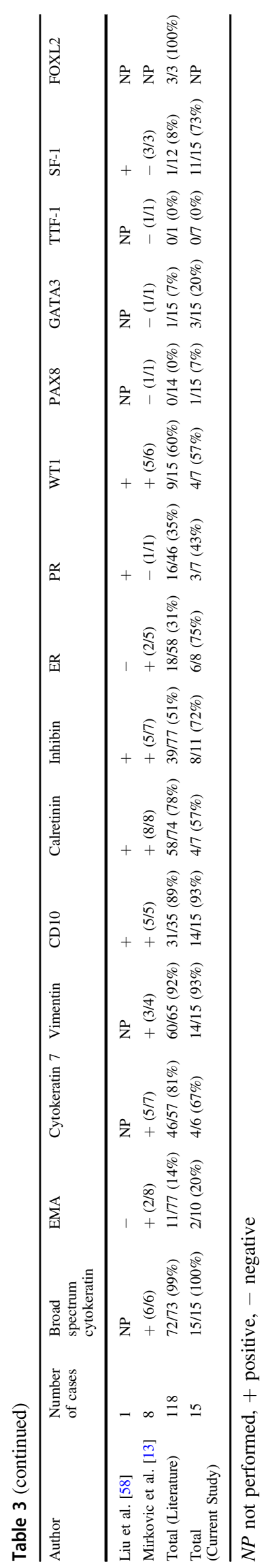

Wolffian origin $[10,11,13,58]$, but most $(73 \%)$ were positive in the current study. This significant discrepancy might potentially be explained by the particular antibody tested. Although our clone was identical to the one used in two of the prior studies [10,11] (antibody information not available for the other two), the antibody was purchased from two different companies. Of note, we initially tried to validate SF-1 using the other company's antibody, but our results were inconsistent. Interestingly, tumors that were SF-1 negative harbored either STK11 or APC mutations. Those that were SF-1 positive were morphologically inconsistent with a sex cord stromal tumor, and also lacked their typical mutations (FOXL2, DICER1).

Although quite uncommon, mesonephric carcinoma of the cervix, as well as the recently described mesonephriclike carcinoma should be briefly discussed [16, 60, 62]. Morphologically, both entities show histologic overlap with Wolffian tumors, primarily due to their multiple architectural patterns and presence of eosinophilic luminal secretions. Mesonephric carcinomas may arise in a background of mesonephric hyperplasia, which has not been noted in any female adnexal tumors of probable Wolffian origin or mesonephric-like carcinomas to date. While true mesonephric carcinomas are predominantly located in the cervix, rarely they are reported in in the corpus, vagina, and ovary $[16,63]$. However, the two tumors previously reported in the ovary likely represent mesonephric-like carcinomas, an entity not yet described at that time, as they lacked an association with mesonephric remnants or rete ovarii [63]. Differentiating between a Wolffian tumor and an ovarian mesonephric-like carcinoma can be challenging, but helpful features include the presence of additional architectural patterns (ductal, papillary, and retiform), an association with endometriosis, tubules with well-defined luminal borders, positive PAX8 and TTF1, negative ER/PR, and presence of KRAS mutations [16, 60,62], all of which would favor the latter.

We were able to sequence $9 / 15(60 \%)$ of our female adnexal tumors of probable Wolffian origin. The remaining $40 \%$ had significantly degraded DNA, which was likely the result of the age of the blocks or other pre-analytical conditions such as the original fixation process. Nevertheless, in these nine tumors, mutations common to mesonephric carcinoma (KRAS, NRAS, chromatin remodeling genes) [17], mesonephric-like carcinoma (KRAS, NRAS, PIK3CA) [60], endometrioid carcinoma (CTNNB1, PIK3CA, ARIDIA, KRAS) [64], sex cord stromal tumor (FOXL2, DICER1) [65], or mesothelioma (BAP1, NF2, CDKN2A) [66] were not identified. Overall, pathogenic mutations were rare, consisting of alterations in STK11 $(n=3), A P C(n=$ $1)$, and MBD4 $(n=1)$. STK11 and APC are discussed in greater detail below, but briefly, MBD4 is a protein that binds methylated DNA, and is mutated in a subset of 
carcinomas, including colorectal and endometrial, that exhibit microsatellite instability [67].

STK11 is a tumor suppressor protein that regulates cell polarity and metabolism. STK11 mutations were previously detected in $2 / 11(18 \%)$ of female adnexal tumors of probable Wolffian origin, including one from a patient with Peutz-Jeghers syndrome [13]. Neither of the two patients with available follow-up in our study had any features of the syndrome. However, we noted that in our three STK11mutated tumors, the tumor cells were surrounded by a myxoid matrix, a feature not present in the other 12 neoplasms. A morphological description was not provided for the two STK11-mutated tumors in Mirkovic et al. [13], thus a comparison could not be performed. Reviewing the morphologic descriptions of Wolffian tumors in the literature highlighted three case reports in which a myxoid background was noted [39, 68]. In the first, Taxy and Battifora noted regions of "anastomosing cords of tumor cells surrounded by a loose myxoid stroma" [68]. We were fortunate to review the original slides of their neoplasm, which revealed an appearance analogous to that seen in our STK11-mutated tumors. Two more recent case reports focused on the identification of Wolffian tumors on cytology specimens, but described the histology specimens as having tumor cells embedded in a myxoid matrix [33, 39]. Since this feature is infrequently described in the literature, we initially considered other diagnoses including an unusual sex cord stromal tumor, a myoepithelial neoplasm, and a metastatic carcinoma, but ultimately favored an unusual variant of a Wolffian tumor. Nonetheless, whether this tumor truly represents a myxoid variant of female adnexal tumor of probable Wolffian origin characterized by STK11 mutations, an unusual presentation of a known neoplasm, or a novel entity merits further investigation.

APC is another a tumor suppressor protein that controls beta-catenin levels, interacts with E-cadherin, and is mutated in familial adenomatous polyposis syndrome. $A P C$, as well as CTNNB1 (the gene encoding beta-catenin) mutations, are characteristic of ovarian microcystic stromal tumors [69]. While these neoplasms may share some morphological and immunohistochemical features with Wolffian tumors, they often have hyalinized bands and intracytoplasmic vacuoles [70, 71], which were not present in our $A P C$-mutated tumor. Furthermore, microcystic stromal tumors are typically keratin and inhibin negative with nuclear expression of beta-catenin [70,71], which is not characteristic of female adnexal tumors of probable Wolffian origin. Since a subset of microcystic stromal tumors have developed in patients with familial adenomatous polyposis syndrome [69], this patient's clinical and family history was reviewed and lacked that association.

Mirkovic et al. previously reported recurrent KMT2D mutations in female adnexal tumors of probable Wolffian origin [13]. In our tumors that were successfully sequenced, we did not identify any pathogenic $K M T 2 D$ variants. Three had KMT2D variants that have been reported as rare inherited alleles in the general population and have been previously classified as benign or likely benign germline variants in the ClinVar database (https://www.ncbi.nlm.nih. gov/clinvar/). In addition, two of the KMT2D variants reported by Mirkovic et al. have also been reported as rare germline variants in population databases (http://exac.broa dinstitute.org), with the third being a missense variant of uncertain significance, and the fourth having a loss of function mutation that would be predicted to have a pathogenic impact.

The current series, as well as two of the prior studies where genomic profiling of female Wolffian tumors was performed did not detect any mutations typical of their morphological mimickers $[13,17]$. However, in the other series, Cossu et al. identified one tumor with a $C T N N B 1$ mutation, and another with a PIK3CA mutation [11]. As previously discussed by Mirkovic et al., CTNNB1 mutations have been described in several tumors including endometrioid carcinomas, Sertoli cell tumor (of testis), microcystic stromal tumor, and extrapancreatic solid pseudopapillary neoplasm [13], while PIK3CA mutations are found in a subset of ovarian clear cell and endometrioid carcinomas [72]. However, the PIK3CA mutation reported by Cossu et al. (p.I391M) [11] is a very common benign germline variant that is seen in $\sim 6 \%$ of the general population and is likely not a real somatic variant in this tumor (http://exac.broadinstitute.org/variant/3178927410-A-G). Furthermore, several other variants reported by Cossu and colleagues are also common germline variants including those reported in MET, KDR, and TP53 genes, and likely do not represent true somatic findings.

In summary, we described the clinicopathological and immunohistochemical features of 15 female tumors of probable Wolffian origin. We highlighted that pathogenic mutations are infrequent in these rare neoplasms, but alterations common to morphological mimickers were not detected. We also identified a subset of presumptive Wolffian tumors with STK11 mutations and copy number variations that had a distinct myxoid matrix, a feature not characteristic of any other tumors in the study. These tumors may be re-evaluated and reclassified in the future as further experience expands.

Acknowledgements The authors would like to thank Dr Jerome Taxy for kindly allowing us to review the slides from his female adnexal tumor of probable Wolffian origin published in Cancer in 1976, and Dr Isabel Serrano for providing follow-up information. We would also like to thank the Human Tissue Resource Center and the Molecular Diagnostic Laboratories at the University of Chicago for performing the immunohistochemical stains and OncoPlus next-generation sequencing, respectively. Finally, we would like to thank Roy Bastien, Devin Close, and Brendan O'Fallon at ARUP Laboratories for performing the Trusight Oncology 500 sequencing. This work was 
presented in part as a platform presentation at the 108th United States and Canadian Academy of Pathology (USCAP) Annual Meeting, National Harbor, MD, USA.

\section{Compliance with ethical standards}

Conflict of interest The authors declare that they have no conflict of interest.

Publisher's note Springer Nature remains neutral with regard to jurisdictional claims in published maps and institutional affiliations.

\section{References}

1. Kariminejad MH, Scully RE. Female adnexal tumor of probable Wolffian origin. A distinctive pathologic entity. Cancer. 1973;31:671-7.

2. Nogales FF. Mesonephric (Wolffian) tumours of the female genital tract: is mesonephric histogenesis a mirage and trap? Curr Diagn Pathol. 1995;2:94-100.

3. Kenny SL, McBride HA, Jamison J, McCluggage WG. Mesonephric adenocarcinomas of the uterine cervix and corpus: HPVnegative neoplasms that are commonly PAX8, CA125, and HMGA2 positive and that may be immunoreactive with TTF1 and hepatocyte nuclear factor 1-beta. Am J Surg Pathol. 2012;36:799-807.

4. Goyal A, Yang B. Differential patterns of PAX8, p16, and ER immunostains in mesonephric lesions and adenocarcinomas of the cervix. Int J Gynecol Pathol. 2014;33:613-9.

5. Roma AA. Mesonephric carcinosarcoma involving uterine cervix and vagina: report of 2 cases with immunohistochemical positivity For PAX2, PAX8, and GATA-3. Int $\mathrm{J}$ Gynecol Pathol. 2014;33:624-9.

6. Howitt BE, Emori MM, Drapkin R, Gaspar C, Barletta JA, Nucci MR, et al. GATA3 is a sensitive and specific marker of benign and malignant mesonephric lesions in the lower female genital tract. Am J Surg Pathol. 2015;39:1411-9.

7. Roma AA, Goyal A, Yang B. Differential expression patterns of GATA3 in uterine mesonephric and nonmesonephric lesions. Int J Gynecol Pathol. 2015;34:480-6.

8. Kim SS, Nam JH, Kim GE, Choi YD, Choi C, Park CS. Mesonephric adenocarcinoma of the uterine corpus: a case report and diagnostic pitfall. Int J Surg Pathol. 2016;24:153-8.

9. Pors J, Cheng A, Leo JM, Kinloch MA, Gilks B, Hoang L. A comparison of GATA3, TTF1, CD10, and calretinin in identifying mesonephric and mesonephric-like carcinomas of the gynecologic tract. Am J Surg Pathol. 2018;42:1596-606.

10. Goyal A, Masand RP, Roma AA. Value of PAX-8 and SF-1 immunohistochemistry in the distinction between female adnexal tumor of probable Wolffian origin and its mimics. Int J Gynecol Pathol. 2016;35:167-75.

11. Cossu A, Casula M, Paliogiannis P, Tanda F, Palomba G, Sini $\mathrm{MC}$, et al. Female adnexal tumors of probable Wolffian origin (FATWO): a case series with next-generation sequencing mutation analysis. Int J Gynecol Pathol. 2017;36:575-81.

12. Hong S, Cui J, Li L, Buscema J, Liggins C, Zheng W. Malignant female adnexal tumor of probable Wolffian origin: case report and literature review. Int J Gynecol Pathol. 2018;37:331-7.

13. Mirkovic J, Dong F, Sholl LM, Garcia E, Lindeman N, MacConaill $\mathrm{L}$, et al. Targeted genomic profiling of female adnexal tumors of probable Wolffian origin (FATWO). Int J Gynecol Pathol. 2018. [Epub ahead of print].

14. Devouassoux-Shisheboran M, Silver SA, Tavassoli FA. Wolffian adnexal tumor, so-called female adnexal tumor of probable
Wolffian origin (FATWO): immunohistochemical evidence in support of a Wolffian origin. Hum Pathol. 1999;30:856-63.

15. Silver SA, Devouassoux-Shisheboran M, Mezzetti TP, Tavassoli FA. Mesonephric adenocarcinomas of the uterine cervix: a study of 11 cases with immunohistochemical findings. Am J Surg Pathol. 2001;25:379-87.

16. Howitt BE, Nucci MR. Mesonephric proliferations of the female genital tract. Pathology. 2018;50:141-50.

17. Mirkovic J, Sholl LM, Garcia E, Lindeman N, MacConaill L, Hirsch M, et al. Targeted genomic profiling reveals recurrent KRAS mutations and gain of chromosome $1 \mathrm{q}$ in mesonephric carcinomas of the female genital tract. Mod Pathol. 2015;28:1504-14.

18. Kadri S, Long BC, Mujacic I, Zhen CJ, Wurst MN, Sharma S, et al. Clinical validation of a next-generation sequencing genomic oncology panel via cross-platform benchmarking against established amplicon sequencing assays. J Mol Diagn. 2017;19:43-56.

19. Haas B, Dobin A, Stransky N, Li B, Yang X, Tickle T, et al. STAR-fusion: fast and accurate fusion transcript detection from RNA-Seq. bioRxiv. 2017;120295. https://doi.org/10.1101/ 120295.

20. Young RH, Scully RE. Ovarian tumors of probable Wolffian origin. A report of 11 cases. Am J Surg Pathol. 1983;7:125-35.

21. Shah R, McCluggage WG. Unclassifiable malignant extraovarian sex cord-stromal tumors: report of 3 cases and review of extraovarian sex cord-stromal tumors. Int $\mathrm{J}$ Gynecol Pathol. 2017;36:438-46.

22. Hughesdon PE. Ovarian tumours of Wolffian or allied nature: their place in ovarian oncology. J Clin Pathol. 1982;35:526-35.

23. Prasad CJ, Ray JA, Kessler S. Female adnexal tumor of Wolffian origin. Arch Pathol Lab Med. 1992;116:189-91.

24. Rahilly MA, Williams AR, Krausz T, Al Nafussi A. Female adnexal tumour of probable Wolffian origin: a clinicopathological and immunohistochemical study of three cases. Histopathology. 1995;26:69-74.

25. Kommoss F, Oliva E, Bhan AK, Young RH, Scully RE. Inhibin expression in ovarian tumors and tumor-like lesions: an immunohistochemical study. Mod Pathol. 1998;11:656-64.

26. Bata MS, Kamal MF. Female adnexal tumour of probable Wolffian origin in a 23-year-old woman. Eur J Obstet Gynecol Reprod Biol. 1999;87:179-82.

27. Sheyn I, Mira JL, Bejarano PA, Husseinzadeh N. Metastatic female adnexal tumor of probable Wolffian origin: a case report and review of the literature. Arch Pathol Lab Med. 2000;124:431-4.

28. Tiltman AJ, Allard U. Female adnexal tumours of probable Wolffian origin: an immunohistochemical study comparing tumours, mesonephric remnants and paramesonephric derivatives. Histopathology. 2001;38:237-42.

29. Ramirez PT, Wolf JK, Malpica A, Deavers MT, Liu J, Broaddus R. Wolffian duct tumors: case reports and review of the literature. Gynecol Oncol. 2002;86:225-30.

30. Ordi J, Romagosa C, Tavassoli FA, Nogales F, Palacin A, Condom E, et al. CD10 expression in epithelial tissues and tumors of the gynecologic tract: a useful marker in the diagnosis of mesonephric, trophoblastic, and clear cell tumors. Am J Surg Pathol. 2003;27:178-86.

31. Steed H, Oza A, Chapman WB, Yaron M, De Petrillo D. Female adnexal tumor of probable Wolffian origin: a clinicopathological case report and a possible new treatment. Int $\mathbf{J}$ Gynecol Cancer. 2004;14:546-50.

32. Atallah D, Rouzier R, Voutsadakis I, Sader-Ghorra C, Azoury J, Camatte S, et al. Malignant female adnexal tumor of probable Wolffian origin relapsing after pregnancy. Gynecol Oncol. 2004;95:402-4. 
33. Halushka MK, Ali SZ. Pathologic quiz case: a 34-year-old woman with an inguinal mass. Female adnexal tumor of probable Wolffian origin. Arch Pathol Lab Med. 2004;128:1301-2.

34. Li CC, Qian ZR, Hirokawa M, Sano T, Pan CC, Hsu CY, et al. Expression of adhesion molecules and $\mathrm{Ki}-67$ in female adnexal tumor of probable Wolffian origin (FATWO): report of two cases and review of the literature. APMIS. 2004;112:390-8.

35. Sivridis E, Giatromanolaki A, Koutlaki N, Anastasiadis P. Malignant female adnexal tumour of probable Wolffian origin: criteria of malignancy. Histopathology. 2005;46:716-8.

36. Karaca M, Sevinc A, Aydin A, Gocmen A, Buyukberber S, Camci $\mathrm{C}$, et al. Female adnexal tumor of probable Wolffian origin diagnosed during the staging evaluation of extranodal diffuse large B-cell lymphoma. Leuk Lymphoma. 2005;46:929-33.

37. Harada O, Ota H, Takagi K, Matsuura H, Hidaka E, Nakayama J. Female adnexal tumor of probable Wolffian origin: morphological, immunohistochemical, and ultrastructural study with c-kit gene analysis. Pathol Int. 2006;56:95-100.

38. Balbi GC, Del Piano L, Labriola D, Visconti S, Monteverde A, Passaro M, et al. Female adnexal tumor of probable Wolffian origin: clinicopathological, immunohistochemical and cytofluorimetric analyses of a 22-year-old virgin. case report. Eur J Gynaecol Oncol. 2006;27:313-6.

39. Tamiolakis D, Anastasiadis P. Metastatic female adnexal tumour of probable Wolffian origin. A histocytopathological correlation. Cytopathology. 2007;18:264-6.

40. Deen S, Duncan TJ, Hammond RH. Malignant female adnexal tumors of probable wolffian origin. Int $\mathbf{J}$ Gynecol Pathol. 2007;26:383-6.

41. Fanghong L, Szallasi A, Young RH. Wolffian tumor of the ovary with a prominent spindle cell component: report of a case with brief discussion of unusual problems in differential diagnosis, and literature review. Int J Surg Pathol. 2008;16:222-5.

42. Liu Y. Metastatic female adnexal tumor of possible Wolffian origin (FATWO) of the appendix demonstrated by FDG PET/CT: the first reported case. Clin Nucl Med. 2011;36:136-7.

43. Al-Agha OM, Huwait HF, Chow C, Yang W, Senz J, Kalloger SE, et al. FOXL2 is a sensitive and specific marker for sex cordstromal tumors of the ovary. Am J Surg Pathol. 2011;35:484-94.

44. Syriac S, Durie N, Kesterson J, Lele S, Mhawech-Fauceglia P. Female adnexal tumor of probable Wolffian origin (FATWO) with recurrence 3 years postsurgery. Int $\mathrm{J}$ Gynecol Pathol. 2011;30:231-5.

45. Heller DS, Kadire B, Cracchiolo B. Malignant female adnexal tumor of probable Wolffian origin: a case report. J Reprod Med. 2011;56:175-7.

46. Tianmin X, Weiqim C, Mianhua C, Xiaocui L, Hongwen G, Min Y. Tumor of the mesosalpinx: case report of a female adnexal tumor of probable Wolffian origin. Eur J Gynaecol Oncol. 2012;33:233-5.

47. Kahyaoglu S, Kahyaoglu I, Sirvan L, Sengul I, Timur H, Mollamahmutoglu L. Female adnexial tumor of probable Wolffian origin (FATWO) without Ki-67 expression reflecting low malignant potential in a 55-year-old woman. Eurasia $\mathrm{J}$ Med. 2012;44:172-5

48. Turkcapar AF, Seckin B, Gungor T, Sirvan L, Mollamahmutoglu L. Diagnosis and management of female adnexal tumor of probable Wolffian origin (FATWO) arising from ovary: a case report. J Turk Ger Gynecol Assoc. 2013;14:56-9.

49. Gupta AK, Srinivasan R, Nijhawan R. Female adnexal tumor of probable Wolffian origin. Indian $\mathrm{J}$ Pathol Microbiol. 2014;57:620-2.

50. Deshimaru R, Fukunaga T, Sato T, Morinaga S, Takahashi M. A case of metastatic female adnexal tumor of probable Wolffian origin. Gynecol Oncol Rep. 2014;10:22-4.
51. Nakamura K, Nakayama K, Miura H, Fujiwaki R, Manabe A, Teshima $\mathrm{S}$, et al. Malignant female adnexal tumor of Wolffian origin (FATWO) positive for CD56: a possible diagnostic role for the biomarker. Eur J Gynaecol Oncol. 2014;35:580-3.

52. Sakai M, Abiko K, Matsumura N, Kondoh E, Yamaguchi K, Minamiguchi S, et al. Two cases of Wolffian tumor with novel magnetic resonance imaging findings reflecting characteristic pathology. J Obstet Gynaecol Res. 2016;42:1046-51.

53. Kwon MJ, Yun MJ, Kim MK. A female adnexal tumor of probable Wolffian origin showing positive O-6-methylguanine-DNA methyltransferase methylation. Obstet Gynecol Sci. 2016;59:328-32.

54. Moro F, Pozzati F, Di Legge A, De Blasis I, Scambia G, Testa AC. Adnexal tumor of probable Wolffian origin arising from retroperitoneal space. Ultrasound Obstet Gynecol. 2017;49:807-8.

55. Du YQ, Song SZ, Ni XC, Wu JG, Wang SL, Jiang BJ, et al. Large Wolffian adnexal tumor of the ovary: a case report and literature review. Oncol Lett. 2017;14:5167-70.

56. Wakayama A, Matsumoto H, Aoyama H, Saio M, Kumagai A, Ooyama $\mathrm{T}$, et al. Recurrent female adnexal tumor of probable Wolffian origin treated with debulking surgery, imatinib and paclitaxel/carboplatin combination chemotherapy: a case report. Oncol Lett. 2017;13:3403-8.

57. Rosen C, Reardon E, Shyu S, Terhune J, Saats P, Ioffe O, et al. Wolffian tumor (female adnexal tumor of Wolffian origin) presenting as a pelvic side wall mass: report of a case. SAGE Open Med Case Rep. 2019;7:2050313X19839534.

58. Liu L, Fang Q, Xing Y. Female adnexal tumor of probable Wolffian origin arising from mesosalpinx: a case report and review. J Obstet Gynaecol Res. 2018;44:1859-63.

59. Deavers MT, Malpica A, Liu J, Broaddus R, Silva EG. Ovarian sex cord-stromal tumors: an immunohistochemical study including a comparison of calretinin and inhibin. Mod Pathol. 2003;16:584-90.

60. Mirkovic J, McFarland M, Garcia E, Sholl LM, Lindeman $\mathrm{N}$, MacConaill L, et al. Targeted genomic profiling reveals recurrent KRAS mutations in mesonephric-like adenocarcinomas of the female genital tract. Am J Surg Pathol. 2018;42: 227-33.

61. Zhao C, Barner R, Vinh TN, McManus K, Dabbs D, Vang R. SF1 is a diagnostically useful immunohistochemical marker and comparable to other sex cord-stromal tumor markers for the differential diagnosis of ovarian sertoli cell tumor. Int $\mathrm{J}$ Gynecol Pathol. 2008;27:507-14.

62. McFarland M, Quick CM, McCluggage WG. Hormone receptornegative, thyroid transcription factor 1-positive uterine and ovarian adenocarcinomas: report of a series of mesonephric-like adenocarcinomas. Histopathology. 2016;68:1013-20.

63. Moerman P, Lurquin E, Vergote I. Mesonephric carcinoma of the ovary: a report of two cases. J Cytol Histol. 2015;6:317.

64. McConechy MK, Ding J, Senz J, Yang W, Melnyk N, Tone AA, et al. Ovarian and endometrial endometrioid carcinomas have distinct CTNNB1 and PTEN mutation profiles. Mod Pathol. 2014;27:128-34.

65. Lim D, Oliva E. Ovarian sex cord-stromal tumours: an update in recent molecular advances. Pathology. 2018;50:178-89.

66. Singhi AD, Krasinskas AM, Choudry HA, Bartlett DL, Pingpank JF, Zeh HJ, et al. The prognostic significance of BAP1, NF2, and CDKN2A in malignant peritoneal mesothelioma. Mod Pathol. 2016;29:14-24.

67. Sjolund AB, Senejani AG, Sweasy JB. MBD4 and TDG: multifaceted DNA glycosylases with ever expanding biological roles. Mutat Res. 2013;743-744:12-25. 
68. Taxy JB, Battifora H. Female adnexal tumor of probable Wolffian origin: evidence of a low grade malignancy. Cancer. 1976;37:2349-54.

69. Lee SH, Koh YW, Roh HJ, Cha HJ, Kwon YS. Ovarian microcystic stromal tumor: a novel extracolonic tumor in familial adenomatous polyposis. Genes Chromosomes Cancer. 2015;54: 353-60.

70. Irving JA, Young RH. Microcystic stromal tumor of the ovary: report of 16 cases of a hitherto uncharacterized distinctive ovarian neoplasm. Am J Surg Pathol. 2009;33:367-75.
71. Irving JA, Lee CH, Yip S, Oliva E, McCluggage WG, Young RH. Microcystic stromal tumor: a distinctive ovarian sex cord-stromal neoplasm characterized by FOXL2, SF-1, WT-1, Cyclin D1, and beta-catenin nuclear expression and CTNNB1 mutations. Am J Surg Pathol. 2015;39:1420-6.

72. Prat J, D'Angelo E, Espinosa I. Ovarian carcinomas: at least five different diseases with distinct histological features and molecular genetics. Hum Pathol. 2018;80:11-27. 